\title{
A test of theory of planned behavior in type II diabetes adherence: The leading role of perceived behavioral control
}

\author{
Illknur Dilekler ${ }^{1} \cdot$ Canay Doğulu $^{2}$ (D) $\cdot$ Özlem Bozo ${ }^{3}$
}

(C) Springer Science+Business Media, LLC, part of Springer Nature 2019

\begin{abstract}
Diabetes mellitus is a health complication that millions of people suffer from all over the world. Type II (non-insulin dependent) diabetes requires many changes in the daily lives of patients, including monitoring blood glucose, following a healthy diet, exercising, and taking medications. Although it is vital for their health, patients generally find it difficult to adhere to their medical regimen. In order to better understand the adherence behaviors of type II diabetes patients, the theory of planned behavior (TPB) was used as the theoretical framework for this study. Ninety type II diabetes patients, who were outpatients of four different hospitals in Ankara, Turkey were administered the TPB tool. The mediation analyses provided support for the mediating role of intention for the attitudes-behavior and subjective norms-behavior relations. The findings did not reveal a mediating role of intention for the PBC-behavior relation but a significant direct effect of $\mathrm{PBC}$ on adherence behavior was found. Overall, it seems important that PBC and the multi-faceted nature of adherence behaviors are considered when designing interventions for type II diabetes patients.
\end{abstract}

Keywords Type II diabetes · Adherence · The theory of planned behavior $\cdot$ Perceived behavioral control · Turkey

Chronic diseases have become an important agenda for health practitioners as they, throughout the world, comprise the major causes of death and disability and there has been an increasing trend in rates of chronic diseases (World Health Organization; WHO 2018). According to worldwide statistics of WHO (2016), the estimated number of people living with diabetes went up from 108 million to 422 million, reflecting a nearly doubled increase in global prevalence. As these statistics indicate, diabetes is a highly prevalent and rapidly increasing chronic disease. In Turkey, diabetes is among the top ten causes of death and has the highest burden of disease along with cardiovascular diseases (WHO 2015). Overall, diabetes is globally considered as a serious public health problem that

Canay Doğulu

canaydogulu@gmail.com

1 Psychological Counseling and Development Center, Bilkent University, 06800 Bilkent, Ankara, Turkey

2 Department of Psychology, Başkent University, Bağlıca Yerleşkesi, Eskișehir Yolu 18. km., 06790 Etimesgut, Ankara, Turkey

3 Department of Psychology, Middle East Technical University, Üniversiteler Mahallesi, Dumlupınar Bulvarı No: 1, 06800 Ankara, Turkey needs to be prevented by controlling related common biological and behavioral risk factors (WHO 2018).

Diabetes is a serious chronic condition resulting from body's inability to maintain glucose homeostasis. Type II diabetes, comprising a great majority of people with diabetes, occurs when the body is not able to effectively use the insulin it produces (WHO 2016). If not controlled, diabetes causes raised blood glucose and this leads to many physical complications in the body, such as heart attack, stroke, kidney failure, leg amputation, vision loss, and nerve damage (American Diabetes Association 2000; WHO 2016). The physical complications may also be accompanied by psychosocial complications such as negative mood (Adriaanse et al. 2005), depression (Lustman and Clouse 2005), isolation (Whiting et al. 2006), and lower perceived quality of life (Caldwell et al. 1998). Thus, in order to prevent these complications that challenge patients' daily lives, at the individual level, diabetes need to be managed by following medical adherence and adopting healthy lifestyles targeted at improving diet and physical activity (WHO 2016). Diabetes adherence, which is basically the degree of agreement between the health-related behavior of an individual with the recommended action or advice proposed by health care providers, includes glucose monitoring, administration of medication, healthy diet, foot care, and physical activity (Albery and Munafò 2008). However, due to its complex treatment taking place over a 
long period of time and its adherence requiring undesirable lifestyle changes, adherence rates for treatment regimen in diabetes are low. Medication adherence ranges from 36.7\% to $67.9 \%$ (Polonsky and Henry 2016) in general and is reported to be around $60 \%$ in Turkey (IQVIA Institute for Human Data Science 2017). The rates are even as low as $30 \%$ for specific behaviors like exercise and diet (Peyrot et al. 2005).

The theory of planned behavior (TPB) provides a sociocognitive framework for explaining engagement in specific volitional behaviors. It was introduced by Ajzen (1985) as a theoretical extension of the theory of reasoned action (TRA) (Fishbein and Ajzen 1975). The theory assumes that behavior can be predicted from intention, which is determined by individual's attitude towards the behavior, subjective norms, and perceived behavioral control (PBC). Attitude towards the behavior consists of beliefs about the outcomes of the behavior (outcome expectancy beliefs) and evaluations of the expected outcomes of the behavior (outcome value). Subjective norms involve the person's perception of what others think one should do (normative beliefs) and the value person gives to behaving in line with others' expectations. PBC, which is the major difference between the TPB and the TRA, is defined as the person's beliefs about the amount of control one has on the behavior (control beliefs) (Ajzen 1985). Ajzen (1991) noted that intentions were conceptualized to be central to behavior change in the TRA; however, literature on Atkinson's theory of achievement motivation and Bandura's concept of selfefficacy necessitated such revision. Unlike the other two predictors of intention (attitudes and subjective norms), PBC is proposed to predict behavior directly. As Ajzen (1991) puts forth, this prediction is based on the reasoning that actual control over different behaviors might vary. Specifically, if the behavior is totally volitional, intention is expected to directly and strongly predict the behavior. On the other hand, if additional constraints are required to engage in that behavior even though the individual has the intention to perform it- the control one perceives on the behavior would be more influential. Hence, PBC was theorized to function as the direct determinant of behavior in case of a weak relation between intention and behavior (Ajzen 1991; Armitage and Conner 2001).

There is a large body of research that has utilized the TPB to explain behavioral processes taking place in various domains (see Ajzen 2018 for an archive). Health seems to be by far the most frequently studied behavioral domain but the theory has also been used to explain behaviors pertaining to relationships (e.g., Byrne and Arias 2004), marketing (e.g., Hasbullah et al. 2014), environment (e.g., De Leeuw et al. 2015), education (Davis et al. 2002), and traffic (Moan 2013) among many others. Further, the efficacy and utility of the TPB have been demonstrated in a number of systematic reviews and metaanalyses (e.g., Armitage and Conner 2001). Considering its significance to health psychology, a great number of studies have been conducted to understand health-related behaviors of individuals on the basis of the TPB and based on these studies many intervention strategies were suggested. Similar to the empirical support for the TPB in general, the findings of these studies provided support for the theory in understanding behaviors such as exercising (Blue 1995), breast cancer examination (Godin et al. 2001), smoking cessation (Bledsoe 2006), and condom use (Albarracin et al. 2001). Similarly, in their metaanalysis study examining the prospective prediction of health-related behaviours with the TPB, McEachan et al. (2011) showed that the TPB strongly predicted futureoriented intention and behaviour across a range of health behaviors including physical activity, dietary, safer sex, risk detection, and abstinence behaviors.

Regarding the management of diabetes, the TPB has been applied to adherence behaviors of patients diagnosed with type I and type II diabetes as well as health behaviors of people with diabetes risk. Starting with risk group studies from UK and US, the TPB-related cognitions for physical activity (Hardeman et al. 2011) as well as exercising and healthy eating behaviors (Blue 2007) have been investigated. While both studies mainly investigated intention as a TPBrelated cognition, Hardeman et al. (2011) also included assessment of actual physical activity in their study. In both studies, PBC significantly predicted intention to engage in health behaviors, indicating the effectiveness of the TPB for intention. However, Hardeman et al. (2011) pointed out that the theory failed to predict behavior and behavior change in risk groups at baseline, 6-, and 12-month follow-ups. These findings with risk groups seem to be limited due to the fact that the participants were not diagnosed with diabetes, thus they did not need to adhere to a diabetes regimen at that time. Hence, either their behaviors were not investigated or the measured health behaviors (i.e., physical activity) were not directly related to management of diabetes.

In addition to research with risk group samples, research with clinical samples provide insights on the usefulness of the TPB in prediction of diabetes-related behaviors. Study findings vary in the extent to which the TPB is effective, that is, whether the model as a whole or only partially with a few TPB components predict adherence behaviors. For instance, two studies from Canada investigating the TPB in relation to physical activity of diabetes patients showed that attitudes, subjective norms, and PBC explained 60\% (Boudreau and Godin 2009) and $40 \%$ (Plotnikoff et al. 2010) of the variance in intention to engage in physical activity. Although these findings support the model in general for physical activity, Ferreira and Pereira (2017) provided only partial support for the TPB in that only attitude and PBC predicted intention.

Research with clinical samples providing partial support for the TPB has also included dietary behavior among diabetes patients. In their study, White et al. (2007) investigated 
engaging in physical activity along with following low-fat diet in both type II diabetes and cardiovascular disease patients from Australia. They found that physical activity was predicted by attitude and PBC, whereas eating behavior was predicted by attitude and subjective norms. In another study on eating behaviors of type II diabetes patients, White et al. (2010) found that intention was predicted by attitude and subjective norms while intention and $\mathrm{PBC}$ were directly related to consumption of food with low saturated fats.

Studies designed to consider multiple aspects of diabetes management from a TPB perspective are relatively scarce. In a study conducted by Gatt and Sammut (2008), the focus was on adherence behaviors for diet, exercise, blood sugar testing, foot care, and medication habits of Maltese diabetes patients. Thus, a composite dependent variable reflecting different behavioral domains of diabetes was used. Gatt and Sammut (2008) found that attitudes, subjective norms, and PBC were important predictors of intention to carry out expected behaviors among people with type II diabetes, with PBC being the strongest predictor of intention. Another study conducted with women diagnosed with type II diabetes (Didarloo et al. 2012) utilized extended TRA by incorporating the components of TRA and self-efficacy. The findings of Didarloo et al.'s (2012) study highlighted the importance of self-efficacy, as it was the strongest predictor of intention and had a direct relation with behavior in an Iranian sample. However, it should be noted that the interchangeability of the concepts of self-efficacy and PBC is relevant here. Ajzen (2011) reviewed and commented on the issue by suggesting that self-efficacy is just one dimension of PBC.

To date, there have been no empirical studies in Turkey investigating the TPB with diabetes patients. Still, there are a few studies examining the effects of positive health beliefs (Kartal and Özsoy 2014), health perceptions (Küçük and Yapar 2016), and attitudes (Kara and Çınar 2011) on type II diabetes patients' adherence. Additionally, two studies conducted with Turkish immigrants living in Netherlands (Lanting et al. 2008; Uitewaal et al. 2005) suggested that self-efficacy is a crucial factor for adherence. Specifically, Uitewaal et al. (2005) found that Turkish patients with low self-efficacy tend to overcomply to the regimen, while Lanting et al. (2008) stated that decreased adherence is related to low levels of selfefficacy. The latter study also emphasized that, in contrast to Dutch participants, for Turkish participants, increased social support is related to higher levels of adherence.

In view of the abovementioned diabetes-related TPB studies, it seems that this line of research varies in the extent to which studies focus on multiple adherence domains and in the extent to which findings provide full or partial support for the model. This subject matter merits further examination due to following reasons: (a) findings depending on diabetes risk-group studies are inevitably limited in terms of generalizing its findings to adherence behaviors of clinical samples, (b) studies examining specific health behaviors of diabetes patients seem to indicate the relative importance of multiple components of the TPB, (c) studies investigating multiple adherence behaviors are limited in terms of both quantity and actual conceptual correspondence to the TPB, and (d) thus far, studies on the TPB have predominantly been conducted in Western populations. A limited number of studies with Turkish samples also lack consistent and coherent results about regimen adherence. Thus, the question remains as to whether the TPB can explain adherence behaviors of Turkish diabetes patients as a whole in terms of both multiplicity of the TPB components and adherence domains. In an effort to provide an answer to this question, the present study aimed to test the TPB components in relation to adherence behaviors of type II diabetes patients in multiple domains. It was hypothesized that intention would mediate the relations of attitude, subjective norms, and $\mathrm{PBC}$ with adherence behaviors.

\section{Method}

\section{Participants}

The sample consisted of 90 type II diabetes patients recruited through convenient sampling. All participants were outpatients of endocrinology departments of different hospitals in Ankara, Turkey. Their diagnosis was confirmed by the physicians who referred the patients to the study after their regular examination at the hospital. The sample included 54 women $(60 \%$; mean age $=53.37, s d=8.93)$ and 36 men $(40 \%$; mean age $=54.47, s d=8.97)$, and their ages ranged between 19 and $72(M=53.81, S D=8.91)$. Participants' socioeconomic status was assessed based on their subjective evaluation; they were asked to evaluate their income as low, middle, or high. Majority of the participants $(n=75,83.30 \%)$ reported their perceived socioeconomic status as middle, and the remaining participants reported that they were members of either high $(n=2$, $2.20 \%)$ or low ( $n=13,14.40 \%)$ SES. The participants have had a history of diabetes for a minimum of one month and a maximum of 504 months $(M=95.67, S D=82.03)$. While 24 participants $(26.70 \%)$ reported using insulin injections, 82 participants $(91.10 \%)$ reported using medications for their illness. The number of the participants who reported using both insulin injections and medications for their diabetes was $16(17.80 \%)$. Moreover, $26.70 \%(n=24)$ of the patients reported that they had difficulty in providing nutrition necessary for their diabetes management. More than half of the sample $(n=59,65.60 \%)$ had at least one other physical or psychological illness. Hypertension $(n=26$, 
$44 \%)$, cardiovascular diseases $(n=10,17 \%)$, and hernia ( $n=10,17 \%$ ) were among the most prevalent diseases that the participants were suffering from.

\section{Procedure}

After obtaining Institutional Review Board approvals, data were collected from two state and two private hospitals in Ankara, Turkey. After the purpose of the study was explained and confidentiality was assured, informed consent was obtained from the participants. Due to reading and visionary difficulties that patients might experience, the questionnaires were applied orally to patients in a meeting room during their hospital visits. Application of each questionnaire took approximately $20 \mathrm{~min}$. Upon administration of the questionnaires, all participants were debriefed.

\section{Measures}

The Theory of Planned Behavior (TPB) Tool The only measure used in this study was the 50-item, 7-point Likert-type questionnaire aimed at measuring the domains of the TPB in relation to type II diabetes. It was developed by Gatt and Sammut (2008) to explore the predictors of self-care behaviors in type II diabetes patients. Consistent with the domains of the TPB, the questionnaire included five subscales measuring attitudes, subjective norms, perceived behavioral control (PBC), behavioral intentions, and behaviors of type II diabetes.

The first subscale of the TPB Tool is about the attitudes towards self-care behaviors of diabetes patients. It consists of 5 items rated on a 7-point scale ranging from unpleasant (1) to pleasant (7) (e.g., For me to eat a healthy diet every day for the next seven days is). Higher scores on this subscale indicate more positive attitudes towards self-care behaviors of diabetes. The second subscale, subjective norms, consists of 10 items rated on a 7-point scale ranging from strongly disagree (1) to strongly agree (7) (e.g., Most people who are important to me would think I should eat a healthy diet every day). Participants, who care more about important people's thoughts about their engagement in diabetes self-care behaviors, score higher on this subscale. The third subscale of TBP Tool measures PBC of the participants. PBC was conceptualized as the patients' perceptions of controllability of and self-efficacy about the illness. The subscale has 15 items (e.g., How much personal control do you feel you have over whether you can eat healthy everyday) rated on a 7-point Likert type scale with 3 items for each dimension of adherence behavior. These items ranged from no control (1) to complete control (7), from not at all confident (1) to very confident (7), and from difficult (1) to easy (7). Higher scores on this subscale indicate higher level of control perceived over self-care behaviors of diabetes. The fourth subscale was about behavioral intentions measured with 10 items rated on a 7-point scale ranging from strongly disagree (1) to strongly agree (7) (e.g., I will try to eat a healthy diet every day). Higher scores on this subscale indicate higher level of intentions to engage in self-care behaviors of diabetes. The last subscale of the TPB Tool was about the self-care behaviors of type II diabetes patients. It included 10 items about diet, exercise, blood sugar testing, foot care, and medication habits such as "How many of the seven days did you test your blood sugar?". Higher scores on this subscale indicate higher levels of engagement in actual diabetes self-care behaviors. Self-care behaviors in the TPB tool correspond to adherence behaviors in our study. Thus, in the rest of the paper the term adherence behavior will be used to refer to the reports of the participants about their actual behavior.

The original tool was developed in a Maltese sample diagnosed with type II diabetes and it was found to have content validity. It had an acceptable level of internal consistency for the subscales of attitudes $(\alpha=.90)$, subjective norms $(\alpha=.90)$, PBC $(\alpha=.85)$, behavioural intentions $(\alpha=.84)$, and moderate level of reliability for self-care behaviors $(\alpha=.50)$. Moreover, test-retest reliability coefficients were .79 for attitude subscale, .89 for subjective norms subscale, .87 for PBC subscale, and .79 for behavioral intention subscale (Gatt and Sammut 2008).

The original tool was developed in English; thus it was translated into Turkish by the authors of the present study. The translation of the tool from English into Turkish was completed by the first two authors who were fluent in Turkish and English. Then, a back-translation was done by the third author who was also fluent in both languages. This back-translation was compared with the original tool by all three authors. At this stage, these two English versions were evaluated to check if the translated version retains the original meaning, and then inconsistencies were resolved (Brislin 1970). The translated version had acceptable internal consistency $(\alpha=.89)$. Subscales of subjective norms $(\alpha=.89)$, PBC $(\alpha=.82)$, and behavioral intention $(\alpha=.84)$ had high reliability values. Cronbach alpha values were relatively lower for attitude $(\alpha=.53)$ and self-care behaviors $(\alpha=.60)$, indicating moderate levels of reliability (Hinton et al. 2004). These subscales were included into the analysis not to disrupt the unity of the tool and the TPB model. In addition, Hair et al. (2014) put forth that Cronbach alpha levels around .60 are acceptable if research is exploratory and/or if other constructs have good reliability values, which is also the case in this study.

\section{Results}

Preliminary analyses were conducted to examine the relations between the demographic and main study variables (i.e., the TPB model variables). Particularly, significant 
correlations and group differences for the TPB variable adherence behavior were inspected to use as covariates later for testing the TPB model with mediation analyses. Based on correlational analyses (see Table 1), duration of diabetes was significantly and positively related to adherence behavior $(r=.25, p<.05)$, indicating that the longer the duration of diabetes, the higher their actual adherence behaviors were. As for group differences, it was found that participants who reported difficulty in food supply ( $m=47.50, s d=12.75)$ were found to adhere to their regimen more than the participants who did not report any difficulty $(m=41.30, s d=9.10), t(88)=-2.55, p<.05$. Accordingly, diabetes duration and food supply difficulty were included as covariates in the mediation analyses.

Considering our small sample size and the resulting potential for increased type I error, a bootstrapping approach was preferred for the main analyses. Accordingly, the TPB model was tested by PROCESS (Preacher and Hayes 2004), an analytic tool which is based on bootstrapping and also allows for controlling for covariates in mediation analyses. For the mediation analyses, the indirect effects of the TPB variables attitudes, subjective norms, and $P B C$ on adherence behavior through intention was tested using bias-corrected bootstrapping derived from 5000 resampling. Each mediation was tested separately so that the effects of the predictors and the covariates on each other are not cancelled out (Hayes 2018; Preacher and Hayes 2004). As Hayes (2018) recommended, Sobel test was used to examine the significance of the mediations. Specifically, an indirect effect is considered as significant when the range of the $95 \%$ confidence interval (CI) derived from 5000 bootstrap resamples excludes zero. Both preliminary and mediation analyses were performed using IBM SPSS (Version 20). An interactive online calculation tool was used to conduct the Sobel test (Preacher and Leonardelli 2001).
Firstly, the indirect effect of attitudes on adherence behavior through intention was examined with diabetes duration and food supply difficulty as covariates. It was found that the indirect effect of attitudes was statistically different from zero (CI $[.17, .86])$ and the Sobel test yielded significant results $(z=2.65, S E=.19, p<.01)$. Thus, intention mediated the relation between attitudes and adherence behavior. In other words, when participants had high levels of intention to adhere to the medical regimen, having positive attitudes toward adherence increased their actual behavioral engagement.

Secondly, the indirect effect of subjective norms on adherence behavior through intention was tested with diabetes duration and food supply difficulty as covariates. The mediation analysis revealed that subjective norms influences adherence behavior indirectly through intention (CI $[.06, .37])$. The Sobel test also showed that this indirect effect was statistically significant $(z=2.97, S E=.06, p<.01)$. Thus, when participants had high levels of intention to adhere to the medical regimen, endorsing subjective norms regarding adherence increased their actual behavioral engagement.

Lastly, the indirect effect of PBC on adherence behavior through intention was tested after controlling for the two covariates. For this indirect effect, the range of the $95 \%$ confidence interval included zero (CI $[-.15, .19])$. That is, intention failed to mediate the PBC-behavior relationship. The significant direct effect, however, suggested that higher levels of PBC is positively related to engagement in adherence behaviors. The direct effects tested for all the mediation analyses can be seen in Table 2.

\section{Discussion}

The aim of the current study was to test the Theory of Planned Behavior (TPB) in an attempt to better understand the

Table 1 Descriptive statistics for and intercorrelations among variables: age, duration, attitudes, subjective norms, perceived behavioral control (PBC), intention, and adherence behavior

\begin{tabular}{|c|c|c|c|c|c|c|c|c|c|c|c|}
\hline \multirow[t]{2}{*}{ Variable } & \multicolumn{7}{|c|}{ Correlations } & \multirow[t]{2}{*}{$M$} & \multirow[t]{2}{*}{$S D$} & \multicolumn{2}{|c|}{ Range } \\
\hline & 1 & 2 & 3 & 4 & 5 & 6 & 7 & & & Min. & Max. \\
\hline 1. Age & - & & & & & & & 53.81 & 8.91 & 19 & 72 \\
\hline 2. Duration & $.43 * *$ & - & & & & & & 95.67 & 82.03 & 1 & 504 \\
\hline 3. Attitudes & $-2.36^{*}$ & .12 & $(.53)$ & & & & & 31.73 & 2.97 & 17 & 35 \\
\hline 4. Subjective Norms & -.52 & .21 & .13 & $(.89)$ & & & & 58.70 & 10.89 & 24 & 70 \\
\hline 5. $\mathrm{PBC}$ & .06 & $.26^{*}$ & $.36^{* *}$ & $.37 * *$ & $(.82)$ & & & 86.52 & 10.79 & 55 & 105 \\
\hline 6. Intention & .02 & $.22 *$ & $.36^{* *}$ & $.47 * *$ & $.72 * *$ & $(.84)$ & & 61.02 & 7.60 & 39 & 70 \\
\hline 7. Adherence Behavior & .14 & $.25^{*}$ & .02 & .14 & $.55^{* *}$ & $.42 * *$ & $(.60)$ & 42.96 & 10.49 & 19 & 69 \\
\hline
\end{tabular}

* Correlation is significant at $p<.05, * *$ Correlation is significant at $p<.01$

Scores shown in parentheses on diagonal are alpha internal consistency reliabilities 
Table 2 Direct effects observed in the mediation analyses

\begin{tabular}{|c|c|c|c|c|c|c|c|c|}
\hline \multirow[t]{3}{*}{ Antecedent } & & \multicolumn{7}{|l|}{ Consequent } \\
\hline & & \multicolumn{3}{|l|}{ Intention } & & \multicolumn{3}{|c|}{ Adherence behavior } \\
\hline & & Coefficient & $S E$ & $p$ & & Coefficient & $S E$ & $p$ \\
\hline Attitudes & $a$ & .86 & .25 & $<.01$ & $c^{\prime}$ & -.60 & .35 & .09 \\
\hline Intention & & - & - & - & $b$ & .59 & .14 & $<.001$ \\
\hline Diabetes duration & & .02 & .00 & .09 & & .02 & .01 & .10 \\
\hline Food supply difficulty & & .76 & 1.70 & .66 & & 5.18 & 2.20 & $<.05$ \\
\hline \multirow[t]{3}{*}{ Constant } & $i_{1}$ & 31.97 & 8.04 & $<.001$ & $i_{2}$ & 22.70 & 11.32 & $<.05$ \\
\hline & & $R^{2}=.16$ & & & & $R^{2}=.27$ & & \\
\hline & & \multicolumn{3}{|c|}{$F(3,86)=5.53, p<.01$} & & \multicolumn{3}{|c|}{$F(4,85)=7.93, p<.001$} \\
\hline Subjective norms & $a$ & .31 & .07 & $<.001$ & $c^{\prime}$ & -.12 & .10 & .27 \\
\hline Intention & & - & - & - & $b$ & .58 & .15 & $<.001$ \\
\hline Diabetes duration & & .01 & .01 & .21 & & .03 & .01 & $<.05$ \\
\hline Food supply difficulty & & .32 & 1.63 & .85 & & 5.45 & 2.41 & $<.05$ \\
\hline \multirow[t]{3}{*}{ Constant } & $i_{1}$ & 41.70 & 3.93 & $<.001$ & $i_{2}$ & 11.00 & 8.17 & .18 \\
\hline & & $R^{2}=.24$ & & & & $R^{2}=.26$ & & \\
\hline & & \multicolumn{3}{|c|}{$F(3,86)=8.85, p<.001$} & & \multicolumn{3}{|c|}{$F(4,85)=7.39, p<.001$} \\
\hline$P B C$ & $a$ & .51 & .06 & $<.001$ & $c^{\prime}$ & .43 & .13 & $<.01$ \\
\hline Intention & & - & - & - & $b$ & .09 & .18 & .63 \\
\hline Diabetes duration & & .00 & .01 & .67 & & .01 & .01 & .25 \\
\hline Food supply difficulty & & -.94 & 1.30 & .47 & & 3.83 & 2.13 & .08 \\
\hline \multirow[t]{3}{*}{ Constant } & $i_{1}$ & 16.91 & 4.63 & $<.001$ & $i_{2}$ & -1.73 & 8.15 & .83 \\
\hline & & \multicolumn{4}{|l|}{$R^{2}=.52$} & \multicolumn{3}{|l|}{$R^{2}=.34$} \\
\hline & & \multicolumn{4}{|c|}{$F(3,86)=31.57, p<.001$} & \multicolumn{3}{|c|}{$F(4,85)=10.75, p<.001$} \\
\hline
\end{tabular}

adherence behaviors of type II diabetes patients. Particularly, the indirect effects of the TPB components attitudes, subjective norms, and $\mathrm{PBC}$ on adherence behavior through intention was tested with separate mediation analyses. The findings provided support for the mediating role of intention for the attitudes-behavior and subjective normsbehavior relations. Mediation findings obtained for attitudes and subjective norms provided support for the TPB model. Specifically, when type II diabetes patients have high levels of intention to adhere to the medical regimen and more positive attitudes toward diabetes-related selfcare behaviors, and endorse subjective norms (i.e., caring about important people's thoughts about one's engagement in diabetes-related self-care behaviors), then they become more likely to perform actual adherence behaviors.

Our findings did not reveal a mediating role of intention for the PBC-behavior relation, indicating that one's level of intention to adhere to medical regimen is not influential in determining the extent to which PBC is positively related with adherence behavior. Still, a significant direct effect of $\mathrm{PBC}$ on adherence behavior was found. That is, adherence to medical regimen was directly explained by how much control the participants felt over their diabetes-related self- care behaviors, which was not the case for attitudes and subjective norms. From a cultural perspective, the observed influence of PBC on adherence behavior without the mediating role of intention, as well as the mediating role of intention for attitudes-behavior and subjective normsbehavior relations, seem to provide support for the crosscultural validity of the TPB in type II diabetes context.

An important finding of this study, thus, is that intention did not function as a mediator for the PBC-behavior relation. This was similar to findings of Zomahoun et al.'s (2016) study which focused on adherence to drug use in diabetes as the behavioral element of the TPB. It seems to be important to reflect on why intention failed to mediate the relation between PBC and adherence behavior. Firstly, as Ajzen (1991) and Armitage and Conner (2001) pointed out, all behaviors may not be equally volitional or the relative importance of predictors might have been influenced by the nature of the particular behavior. For instance, taking pills might require less effort and motivation than exercising or patients might not consider unfavorable consequences of poor foot care as much as blood monitoring. In fact, factors that have been found to be influential in diabetes-related adherence behaviors might have a hindering effect for the translation of intention into actual 
behavioural engagement. Though these factors are not the focus of the TPB, it is known that mindfulness, awareness of attention, environmental cues, and inner experiences (Chatzisarantis and Hagger 2007), individual differences in executive functioning (Hall et al. 2008), coping planning (Scholz et al. 2008), and problem solving (Hill-Briggs 2003) may influence adherence levels to diabetes regimen. Compared to behaviors that require less effort and planning (such as drug usage), behaviors that require more effort (such as exercising) might depend more on factors such as coping planning and problem solving. These possibilities seem to be good candidates for further investigation in the TPB research.

The findings of the present study further provide support for the TPB reasoning in understanding adherence behaviors of type II diabetes patients in Turkey. Particularly, our findings point out that diabetes-related self-care behaviors comprising treatment adherence are not totally volitional; instead, they require additional constraints which render intention ineffective (Ajzen 1991; Armitage and Conner 2001). Further, in the present study, we found that participants who had difficulty in food supply reported higher levels of adherence. This finding can be interpreted as further supporting the view that it might be the extent to which patients perceive control over their adherence behavior, rather than their actual resources, that is important for adherence when it is potentially hindered by extraneous factors such as food supply difficulty. In this sense, the emergence of PBC as a key predictor of adherence behavior can be considered as the most important contribution of this study to the field.

Our findings are also similar to Gatt and Sammut's findings (Gatt and Sammut 2008) in that both studies revealed that PBC directly predicted adherence behaviors of individuals with type II diabetes. Supporting these findings, in a review study investigating the applications of the TPB to healthrelated behaviors (Godin and Kok 1996), PBC was found to be a strong and also the only direct predictor of behavior in half of the studies reviewed on health behaviors. Furthermore, it explained additional $13 \%$ and $12 \%$ of variance in intention and behaviors over and above attitudes and subjective norms. Though this review study is based on peer-reviewed publications during 1985-1996, research evidence has also been accumulating in recent years to support the distinctive role of PBC in predicting health behaviors of individuals with diabetes (e.g., Ajzen 2011; Blue 2007; Didarloo et al. 2012; Taylor et al. 2006; White et al. 2007, 2010).

Abovementioned factors can be regarded as being related to individual's intrapersonal processing about adherence to diabetes regimen. However, research has revealed that interpersonal interactions and social conditions also play a role. Studies have shown that perceptual differences between patients and physicians in terms of diabetes seriousness (Clark and Hampson 2003), obstacles (Vermeire et al. 2007) and perceived barriers to adherence (Nagelkerk et al. 2006) as well as health-related quality of life (Maddigan et al. 2005) influence adherence behaviors of type II diabetes patients. Such difference between patients' and health care professionals' beliefs about diabetes might also be complicating the mediating role of intention for PBC-behavior relation. Furthermore, as related to health care professionals' and patients' interaction, the extent to which patients view their physicians competent in addition to their own perceived self-efficacy has been found to be related to behavior modification (Imai et al. 2017). As have been discussed by Perwitasari and Urbayatun (2016), institution characteristics might also be influential in supporting patients on ways of coping with the disease and adhering to its medical regimen.

Although more than one health institution was visited for this study in order to overcome the possible effects of organizational factors, as researchers we did not have in-depth information about patients-health care system interaction in the four hospitals where data collection took place. Particularly, it might be that the four hospitals differ with respect to health care professionals' characteristics as well as health care politics, patient preferences, and quality of relationship between professionals and patients. For instance, some of the participants mentioned that they attended the hospital's educational meetings about diabetes management while some others did not. Such differences might have influenced our findings. Further studies which take these organizational differences into account are therefore recommended to better understand the role of the TPB dynamics in adherence to type II diabetes regimen.

Pointing out the importance of social context, Ajzen (2011) did propose that investigation of background factors is enriching especially for habit formation as it is the case for major lifestyle changes diabetes requires. Jones et al. (2014) identified several factors as barriers and facilitators at broader levels for type II diabetes management, which would guide future studies in extending their scope. These factors included intrapersonal (illness denial, motivation, knowledge and skills, and lack of time), interpersonal (stress and relationships), organisational (access to recommended foods, transport, health professionals, and exercise options), and societal (engagement and societal attitudes; e.g., disengagement from community, unemployment, lack of meaningful roles in society, isolation, and negative attitudes of society) conditions (Jones et al. 2014). Thus, to develop a full psychological picture of adherence to type II diabetes regimen, further studies focusing on contextual and interpersonal factors in addition to factors accounted by the TPB model are suggested.

In addition to the contributions explained above, the present study stands out in several respects. Particularly, this study is the first in Turkey to test the TPB with type II diabetes patients, a clinical sample. In order to be able to control for possible confounding variables, various diabetes-related demographic variables were also included in our study. In this 
sense, delineating the influence of various diabetes-related (e.g., food supply, difficulty in food supply) sociodemographic variables was rendered possible to some extent. Furthermore, the current study attempted to understand a broad range of behaviors involved in diabetes regimen. Previous research on the application of the TPB to diabetes-related health behaviors mainly relied on specific behaviors, such as physical activity and dietary behaviors. As a matter of fact, the decision of which behaviors of diabetes regimen should be included while testing the TPB seems to be a challenging one. Assessment of the TPB components with a more holistic approach in terms of medical regimen seems to be important, as the daily activities of patients include them all. Yet, different dimensions of diabetes regimen might yield more specific findings, since in that case each individual behavior is evaluated in terms of its own individual (e.g., level of individual effort) and environmental (e.g., physical and economic conditions) requirements as discussed earlier. Likewise, Gatt and Sammut (2008) found that although PBC was the strongest predictor of the model, blood-monitoring was relatively more strongly predicted by $\mathrm{PBC}$ compared to other domains of diabetes regimen. Therefore, in future studies or meta-analyses, the differences between these two research approaches can be addressed.

The current study is not without its limitations. Due to the retrospective nature of adherence measurement, participants might have filled the TPB tool under the influence of recall bias. In other words, they might have unintentionally or intentionally distorted their reports of adherence behaviors in the previous week. Also, since the TPB tool was administered orally by the researchers, the probability of obtaining socially desirable responses by the participants might have increased. Cultural characteristics might have also played a role in this increase in social desirability. Our participants, as members of a relatively collectivistic culture (Hofstede 2001), might have experienced the need to maintain positive and harmonious relations with the interviewer (Johnson and Van de Vijver 2003). Still, as Armitage and Conner (2001) have suggested, social desirability in the TPB studies is trivial.

A further limitation of the present research is that the two subscales of the Turkish version of the TPB tool (i.e., attitudes and adherence behavior) were moderately reliable. These subscales were included in the study due to reasons explained in the Method section. Still, there seems to be substantial need for a thorough adaptation of the tool or development of a robust measurement. Moreover, although the sample size of the study was statistically acceptable, some limitations can arise when the diversity of the participants is considered. The sample of the study did only include patients visiting their physicians regularly, but not those who do not or cannot go to hospital. In other words, our sample might not be representative of type II diabetes patients who do not or cannot attend to their regular visits and this might have confounded the generalizability of our findings. In addition to problems in reaching to patients with diverse characteristics, difficulty in contacting patients multiple times led to a cross-sectional study design, which enabled us to reveal just a snapshot of their adherence behaviors and related factors. Thus, it is crucial that future studies take the diversity of patients into account and employ longitudinal designs in order to increase the validity of findings and their predictive power in this field of research.

In conclusion, despite its limitations, the present study contributes to health psychology literature by examining the implementation of the TPB to adherence behaviors of type II diabetes patients in a non-Western culture. Our findings demonstrated the mediating role of intention for the attitudes-behavior and subjective norms-behavior relations, but not for $\mathrm{PBC}$-behavior relation. Still, $\mathrm{PBC}$ was found to directly predict adherence behaviors of type II diabetes patients. Although the findings should be interpreted with caution, the need to consider $\mathrm{PBC}$ as a crucial aspect of diabetes management is well pointed out, as consistent with theory and previous research. As an implication, it might be that for patients similar to our sample characteristics, professionals should make an effort to facilitate the feeling of control their patients feel over different domains of adherence including glucose monitoring, medication, diet, physical activity, and foot care practices. While doing this, it is also important to keep in mind that the individual patient is embedded in a larger context consisting of social, cultural, and economic dynamics. Hence, there is a need for adopting a more comprehensive approach to behavioral management of type II diabetes adherence, taking into account these socio-cultural dynamics as it is the case for many medical conditions.

Acknowledgments The authors would like to thank Halil Pak for his help in data analysis.

\section{Compliance with Ethical Standards}

Conflict of Interest On behalf of all authors, the corresponding author states that there is no conflict of interest.

Ethical Approval This study obtained ethics approval from Middle East Technical University Human Subjects Ethics Committee and administrative approval from Turkish Republic Ministry of Health. All procedures performed in this study involving human participants were in accordance with the ethical standards of the institutional and/or national research committee and with the 1964 Helsinki declaration and its later amendments or comparable ethical standards.

Informed Consent Informed consent was obtained from all individual participants included in the study. 


\section{References}

Adriaanse, M. C., Dekker, J. M., Spijkerman, A. M. W., Twisk, J. W. R., Nijpels, G., Ploeg, H. M., et al. (2005). Diabetes-related symptoms and negative mood in participants of a targeted population-screening program for type 2 diabetes: The Hoorn screening study. Quality of Life Research, 14, 1501-1509.

Ajzen, I. (1985). From intentions to actions: A theory of planned behavior. In J. Kuhl \& J. Beckman (Eds.), Action-control: From cognition to behavior (pp. 11-39). Heidelberg: Springer.

Ajzen, I. (1991). The theory of planned behavior. Organizational Behavior and Human Decision Processes, 50(2), 179-211.

Ajzen, I. (2011). The theory of planned behaviour: Reactions and reflections. Psychology \& Health, 26(9), 1113-1127.

Ajzen, I. (2018). Theory of planned behavior: A bibliography. Retrieved February, 2019, from http://people.umass.edu/aizen/tpbrefs.html

Albarracin, D., Johnson, B. T., Fishbein, M., \& Muellerleile, P. A. (2001). Theories of reasoned action and planned behavior as models of condom use: A meta-analysis. Psychological Bulletin, 127(1), $142-161$.

Albery, I. P., \& Munafò, M. (2008). Key concepts in health psychology. Los Angeles: SAGE Publications.

American Diabetes Association. (2000). Type 2 diabetes in children and adolescents. Pediatrics, 105(3), 671-680.

Armitage, C. J., \& Conner, M. (2001). Efficacy of the theory of planned behaviour: A meta-analytic review. British Journal of Social Psychology, 40(4), 471-499.

Bledsoe, L. K. (2006). Smoking cessation: An application of theory of planned behavior to understanding progress through stages of change. Addictive Behaviors, 31(7), 1271-1276.

Blue, C. L. (1995). The predictive capacity of the theory of reasoned action and the theory of planned behavior in exercise research: An integrated literature review. Research in Nursing and Health, 18(2), $105-121$.

Blue, C. L. (2007). Does the theory of planned behavior identify diabetesrelated intentions for cognitions to be physically active and eat a healthy diet? Public Health Nursing, 24(2), 141-150.

Boudreau, F., \& Godin, G. (2009). Understanding physical activity intentions among French Canadians with type 2 diabetes: An extension of Ajzen's theory of planned behaviour. International Journal of Behavioral Nutrition and Physical Activity, 6, 35. https://doi.org/ 10.1186/1479-5868-6-35

Brislin, R. W. (1970). Back-translation for cross-cultural research. Journal of Cross-Cultural Psychology, 1, 185-216. https://doi.org/ $10.1177 / 135910457000100301$

Byrne, C. A., \& Arias, I. (2004). Predicting women's intentions to leave abusive relationships: An application of the theory of planned behavior. Journal of Applied Social Psychology, 34, 2586-2601.

Caldwell, E. M., Baxter, J., Mitchell, C. M., Shetterly, S. M., \& Hamman, R. F. (1998). The association of non-insulin-dependent diabetes mellitus with perceived quality of life in a biethnic population: The San Luis Valley diabetes study. American Journal of Public Health, 88(8), 1225-1229.

Chatzisarantis, N. L. D., \& Hagger, M. S. (2007). Mindfulness and the intention-behavior relationship within the theory of planned behavior. Personality and Social Psychology Bulletin, 33, 663-676.

Clark, M., \& Hampson, S. E. (2003). Comparison of patients' and health care professionals' beliefs about and attitudes towards type 2 diabetes. Diabetic Medicine, 20, 152-154.

Davis, L. E., Ajzen, I., Saunders, J., \& Williams, T. (2002). The decision of African American students to complete high school: An application of the theory of planned behavior. Journal of Educational Psychology, 94, 810-819.

De Leeuw, A., Valois, P., Ajzen, I., \& Schmidt, P. (2015). Using the theory of planned behavior to identify key beliefs underlying pro- environmental behavior in high-school students: Implications for educational interventions. Journal of Environmental Psychology, 42, 128-138.

Didarloo, A. R., Shojaeizadeh, D., Asl, R. G., Habibzadeh, H., Niknami, S., \& Pourali, R. (2012). Prediction of self-management behavior among Iranian women with type 2 diabetes: Application of the theory of reasoned action along with self-efficacy (ETRA). Iranian Red Crescent Medical Journal, 14(2), 86-95.

Ferreira, G., \& Pereira, M. G. (2017). Physical activity: The importance of the extended theory of planned behavior in type 2 diabetes patients. Journal of Health Psychology, 22(10), 1312-1321.

Fishbein, M., \& Ajzen, I. (1975). Belief, attitude, intention, and behavior: An introduction to theory and research. Reading: Addison-Wesley.

Gatt, S., \& Sammut, R. (2008). An exploratory study of predictors of selfcare behaviour in persons with type 2 diabetes. International Journal of Nursing Studies, 45, 1525-1533.

Godin, G., \& Kok, G. (1996). The theory of planned behavior: A review of its applications to health-related behaviors. American Journal of Health Promotion, 11(2), 87-98.

Godin, G., Gagne, C., Maziade, J., Moreault, L., Beaulieu, D., \& Morel, S. (2001). Breast cancer: The intention to have a mammography and a clinical breast examination-application of the theory of planned behavior. Psychology and Health, 16(4), 423-441.

Hair, J. F., Black, W. C., Babin, B. J., \& Anderson, R. E. (2014). Multivariate data analysis: $\left(7^{\text {th }}\right.$ ed.). Harlow: Pearson Education Limited.

Hall, P. A., Fong, G. T., Epp, L. J., \& Elias, L. J. (2008). Executive function moderates the intention-behavior link for physical activity and dietary behavior. Psychology and Health, 23(3), 309-326.

Hardeman, W., Kinmonth, A. L., Michie, S., \& Sutton, S. (2011). Theory of planned behaviour cognitions do not predict selfreported or objective physical activity levels or change in the ProActive trial. British Journal of Health Psychology, 16(1), 135-150.

Hasbullah, N., Mahajar, A. J., \& Salleh, M. I. (2014). A conceptual framework of extending the theory of planned behavior: The role of service quality and trust in the consumer cooperatives. International Journal of Business and Social Science, 5(12), $142-148$.

Hayes, A. F. (2018). Introduction to mediation, moderation, and conditional process analysis: A regression-based approach. New York: Guilford Publications.

Hill-Briggs, F. (2003). Problem solving in diabetes self-management: A model of chronic illness self-management behavior. Annals of Behavioral Medicine, 25(3), 182-193.

Hinton, P. R., Brownlow, C., McMurray, I., \& Cozens, B. (2004). SPSS explained. London: Routledge.

Hofstede, G. (2001). Culture's consequences: Comparing values (2nd ed.). California: Sage Publications Inc.

Imai, H., Furukawa, T. A., Hayashi, S. U., Goto, A., Izumi, K., Hayashino, Y., Noda, M., \& J-DOIT2 Study Group. (2017). Risk perception, self-efficacy, trust for physician, depression, and behavior modification in diabetic patients. Journal of Health Psychology 6(35), 1-11. https://doi.org/10.1177/1359105317718057.

IQVIA Institute for Human Data Science (2017). Türkiye'de tip 2 diyabet tedavisinde uyum ve sürekliliğin geliștirilmesi: Kaçınılabilir ekonomik ve toplumsal yüke yaklașım nasıl olmalı? Retrieved February, 2019, from https://www.iqvia.com/tr-tr/institute/reports/ diabetes-therapy-adherence-and-persistence-in-turkey

Johnson, T. P., \& Van de Vijver, F. J. (2003). Social desirability in crosscultural research. In J. A. Harkness, F. J. R. Van de Vijver, \& P. P. Mohler (Eds.), Cross-cultural survey methods (pp. 195-204). New Jersey: John Wiley \& Sons.

Jones, L., Crabb, S., Turnbull, D., \& Oxlad, M. (2014). Barriers and facilitators to effective type 2 diabetes management in a rural 
context: A qualitative study with diabetic patients and health professionals. Journal of Health Psychology, 19(3), 441-453.

Kara, K., \& Çinar, S. (2011). The relation between diabetes care profile and diabetic control variables. Journal of Medical Sciences, 1(2), 57-63. https://doi.org/10.5505/kjms.2011.41736

Kartal, A., \& Özsoy, S. A. (2014). Effect of planned diabetes education on health beliefs and metabolic control in type 2 diabetes patients. Journal of Hacettepe University Faculty of Nursing, 1(2), 1-15.

Küçük, E., \& Yapar, K. (2016). Health perception, health-related behaviors, and medication adherence of patients with type II diabetes: A study in the Black Sea region of Turkey. TAF Preventive Medicine Bulletin, 15(4), 285-292. https://doi.org/10.5455/pmb.11446795532

Lanting, L. C., Joung, I. M., Vogel, I., Bootsma, A. H., Lamberts, S. W. J., \& Mackenbach, J. P. (2008). Ethnic differences in outcomes of diabetes care and the role of self-management behavior. Patient Education and Counseling, 72(1), 146-154.

Lustman, P. J., \& Clouse, R. E. (2005). Depression in diabetic patients: The relationship between mood and glycemic control. Journal of Diabetes and its Complications, 19, 113-122.

Maddigan, S. L., Majumdar, S. R., \& Johnson, J. A. (2005). Understanding the complex associations between patient-provider relationships, self-care providers, and health-related quality of life in type 2 diabetes: A structural equation modeling approach. Quality of Life Research, 14, 1489-1500.

McEachan, R. R. C., Conner, M., Taylor, N. J., \& Lawton, R. J. (2011). Prospective prediction of health-related behaviours with the theory of planned behaviour: A meta-analysis. Health Psychology Review, $5(2), 97-144$.

Moan, I. S. (2013). Whether or not to ride with an intoxicated driver: Predicting intentions using an extended version of the theory of planned behaviour. Transportation Research Part F: Traffic Psychology and Behaviour, 20, 193-205. https://doi.org/10.1016/j. trf.2013.08.001.

Nagelkerk, J., Reick, K., \& Meengs, L. (2006). Perceived barriers and effective strategies to diabetes self-management. Journal of Advanced Nursing, 54(2), 151-158.

Perwitasari, D. A., \& Urbayatun, S. (2016). Treatment adherence and quality of life in diabetes mellitus patients in Indonesia. $S A G E$ Open, 6(2), 1-7.

Peyrot, M., Rubin, R. R., Lauritzen, T., Snoek, F. J., Matthews, D. R., \& Skovlund, S. E. (2005). Psychosocial problems and barriers to improved diabetes management: Results of the cross-National Diabetes Attitudes, wishes and needs (DAWN) study. Diabetic Medicine, 22(10), 1379-1385.

Plotnikoff, R. C., Lippke, S., Courneya, K., Birkett, N., \& Sigal, R. (2010). Physical activity and diabetes: An application of the theory of planned behaviour to explain physical activity for type 1 and type 2 diabetes in an adult population sample. Psychology \&Health, 25(1), 7-23.

Polonsky, W. H., \& Henry, R. R. (2016). Poor medication adherence in type 2 diabetes: Recognizing the scope of the problem and its key contributors. Patient Preference and Adherence, 10, 1299-1307.
Preacher, K. J., \& Hayes, A. F. (2004). SPSS and SAS procedures for estimating indirect effects in simple mediation models. Behavior Research Methods, Instruments, and Computers, 36(4), 717-731.

Preacher, K. J., \& Leonardelli, G. J. (2001). Calculation for the Sobel test: An interactive calculation tool for mediation tests. Retrieved February, 2019, from http://quantpsy.org/sobel/sobel.htm

Scholz, U., Schüz, B., Ziegelmann, J. P., Lippke, S., \& Schwarzer, R. (2008). Beyond behavioral intentions: Planning mediates between intentions and physical activity. British Journal of Health Psychology, 13, 479-494.

Taylor, D., Bury, M., Campling, N., Carter, S., Garfied, S., Newbould, J., \& Rennie, T. (2006). A Review of the use of the Health Belief Model (HBM), the Theory of Reasoned Action (TRA), the Theory of Planned Behaviour (TPB) and the Trans-Theoretical Model (TTM) to study and predict health related behaviour change. London: National Institute for health and clinical excellence Retrieved February, 2019, from https://www.nice.org.uk/guidance/ph6/ resources/behaviour-change-taylor-et-al-models-review2

Uitewaal, P., Hoes, A., \& Thomas, S. (2005). Diabetes education on Turkish immigrant diabetics: Predictors of compliance. Patient Education and Counseling, 57(2), 158-161.

Vermeire, E., et al. (2007). Obstacles to adherence in living with type-2 diabetes: An international qualitative study using meta-ethnography. Primary Care Diabetes, 1(1), 25-33.

White, K. M., Terry, D. J., Troup, C., \& Rempel, L. A. (2007). Behavioral, normative and control beliefs underlying low-fat dietary and regular physical activity behaviors for adults diagnosed with type 2 diabetes and/or cardiovascular disease. Psychology, Health and Medicine, 12(4), 485-494.

White, K. M., Terry, D. J., Troup, C., Rempel, L. A., \& Norman, P. (2010). Predicting the consumption of foods low in saturated fats among people diagnosed with type 2 diabetes and cardiovascular disease. The role of planning in the theory of planned behaviour. Appetite, 55(2), 348-354.

Whiting, M., Scammell, A., Gray, J., Schepers, A. K., \& Bifulco, A. (2006). Managing type 2 diabetes and depression in primary care. Primary Care Mental Health, 4, 175-184.

WHO (2015). Turkey: WHO statistical profile. Retrieved February, 2019, from http://www.who.int/gho/countries/tur.pdf?ua=1

WHO (2016). Global report on diabetes. Retrieved February, 2019, from http://www.who.int/diabetes/global-report/en/

WHO (2018). Integrated chronic disease prevention and control. Retrieved February, 2019, from http://www.who.int/chp/about/ integrated $\mathrm{cd} / \mathrm{en} /$

Zomahoun, H. T. V., Moisan, J., Lauzier, S., Guillaumie, L., Grégoire, J. P., \& Guénette, L. (2016). Predicting noninsulin antidiabetic drug adherence using a theoretical framework based on the theory of planned behavior in adults with type 2 diabetes: A prospective study. Medicine, 95(15), e2954. https://doi.org/10.1097/MD. 0000000000002954

Publisher's note Springer Nature remains neutral with regard to jurisdictional claims in published maps and institutional affiliations. 